\title{
Research on the Relation Between Government Treasury Cash Management and Monetary Policy
}

\author{
Ke Gao ${ }^{1,2}$, Kehan $\mathrm{Li}^{3}$, Tao Wang ${ }^{4}$ \\ ${ }^{1}$ School of Social Sciences, Tsinghua University, Beijing, P. R. China \\ ${ }^{2}$ Bank of Weifang, Weifang, P. R. China \\ ${ }^{3}$ The Center for Economic Research, Shandong University, Jinan, P. R. China \\ ${ }^{4}$ Guanghua School of Management, Peking University, Beijing, P. R. China
}

\section{Email address:}

gkfly@126.com (Ke Gao),hulahulaxiaomuma@163.com (Kehan Li),manutdwangtao@126.com (Tao Wang)

\section{To cite this article:}

Ke Gao, Kehan Li, Tao Wang. Research on the Relation Between Government Treasury Cash Management and Monetary Policy. International Journal of Business and Economics Research. Vol. 8, No. 5, 2019, pp. 314-319. doi: 10.11648/j.ijber.20190805.18

Received: April 4, 2019; Accepted: August 3, 2019; Published: August 27, 2019

\begin{abstract}
After more than ten years of endeavors and efforts, the reform of the financial treasury management system has made significant progress, and functions such as budget execution management and monitoring, financial financing and financial management, financial operation information analysis and reflection, macroeconomic regulation and control, and policy implementation have been basically established. With the steady implementation of the central treasury cash management, local treasury cash management has gradually been pushed forward. International experience shows that a sound treasury cash management system must not only achieve centralized control over treasury funds, but also be able to work closely with monetary policy to effectively invest and finance treasury cash. In this paper, the empirical analysis is carried out by using the econometric model. The results show that the positive impact of the treasury cash management operation has a negative impact on the money supply M1and M2, and the reaction trajectory presents a positive U-shape, which is analyzed from the specific response. The treasury cash management operation has less impact on M1, while the impact on M2 has a volatility characteristic.
\end{abstract}

Keywords: Treasury Cash Management, Monetary Policy, Commercial Bank Time Deposit

\section{Introduction}

The treasury cash management organization structure is at the intersection of the functions of the financial department and the financial department. The financial funds and social funds will be dynamically cycled through the treasury cash management system. To a certain extent, the treasury cash management is an important connection point between China's fiscal policy and monetary policy. With the continuous expansion of the treasury cash management operation, the impact of treasury cash management on monetary policy has been increasingly concerned by the academic community. For example, the operational methods and operational mechanisms of treasury cash management affect the effectiveness of monetary policy implementation. The increase in the volatility of the balance fund further increases the uncertainty of monetary policy by hedging the money supply. In the central and local treasury cash management practices, the system construction of the treasury cash forecasting system has not been perfected and improved, which has increased the difficulty of monetary policy formulation and implementation to a certain extent, and the dynamic inconsistency of macroeconomic policies has gradually become prominent. Therefore, studying the impact of treasury cash management on monetary policy is significant.

Hrung [1] believes that the management of fiscal funds directly affects the implementation of monetary policy, because the net flow of funds into and out of the banking industry generally has to be offset by open market operations. Many scholars have studied the negative impact of treasury funds investment in the money market on the effects of monetary policy. Lynch, Shamsub, and Onwujuba [2] studied the loss of derivatives investment in some US government 
investment groups in the first half of the 1990s and found that although the losses were from derivatives, the actual cause of the losses was a violation of public fund prudence. Jone and Bowrey [3] conducted an in-depth study of the significant losses caused by the investment in structural financial products of the New South Wales local government in the fiscal year 2006-2007. The local government's investment mistakes in New South Wales not only caused huge losses, but also had a significant impact on the banking financial system, which has affected the stability of the money market. Byexamining the impact of economic policy uncertainty on aggregate bank credit growth firstly, Bordo, Duca and Koch [4] founded that under the mixed treasury system of the central bank and commercial banks, since the central bank's treasury maintains a relatively stable treasury stock at the optimal scale, the size of the central bank's treasury has changed little, and its impact on the base currency is small. The bank's treasury funds have become an important source of money supply. At this time, the impact of treasury funds on monetary policy is mainly concentrated in credit channels. Chen Jianqi and Zhang Yuan [5] constructs the analysis framework of the treasury cash transfer commercial bank, which shows that the treasury cash transfer commercial bank will still influence the money supply policy through the asset-liability structure of commercial banks. The treasury cash agreement time deposits will increase the proportion of commercial banks' time deposits to demand deposits. In order to influence the reserve level and credit capacity of commercial banks, the treasury cash requires commercial banks to provide collateral. The higher the mortgage ratio, the more reserve banks must reserve to buy bonds, and the treasury cash can be transferred to commercial banks. The decline in funds led commercial banks to seek more reserve funds from the central bank, so that the increase in treasury cash will cause interest rate levels to rise, and the level of equilibrium credit will be changed through the credit transmission mechanism, eventually causing fluctuations in the level of money supply. Wang Wensu, Zhou Jiannan, and Ning Fangjing [6] discussed the coordination mode between treasury cash management and monetary policy from the two levels of active coordination and passive coordination. It is considered that the passive coordination mode is the optimal coordination mode, which will not hinder the use of treasury cash. The increase in efficiency will not cause passive coordination of the additional burden on the overall economic level. Ye Xiaodong and Du Jinxi [7] uses the monthly data from 2002 to 2012 and the cointegration regression method to empirically analyze the relationship between the central bank's treasury cash and money supply, which shows that the central bank's treasury cash and cash in circulation existslong-term stable equilibrium relationship and the increase in cash in the treasury of the central bank led to an increase in cash in circulation. The conclusion also shown that the amount of cash in the treasury of the central bank remains stable or slightly increased is beneficial to the implementation of the central bank's monetary policy. Based on the monthly data of the national treasury cash balance from 2007 to 2012, Bai Yanfeng, Li
Longyu and Jin Wei [8] use the VAR model to study the dynamic response mechanism between the treasury cash balance changes and China's macroeconomic variables, which found that the changes in China's treasury cash balance are affected by changes in macroeconomic factors. Not significant, and the changes in the treasury cash balance will have a certain degree of impact on macro variables such as GDP, money supply, and consumer price index. Yang Yuxia, Lou Qingyi [9] uses the cointegration method and the error correction model to test whether there is a long-term cointegration effect and a balanced bias adjustment mechanism effect between the change of the treasury fund balance and the monetary policy intermediate target. The results reflect that the change in the balance of long-term treasury funds has a negative effect on the intermediate target of monetary policy. In the short-term, there is a negative feedback mechanism, and the long-term Chinese bank funds have a greater impact on the money supply. Based on the central bank's balance sheet structure, Zhang Xiaobin [10] constructs an analytical framework for the impact of changes in treasury stocks on money supply, and empirically analyzes the impact of changes in treasury stocks on the changes in the money supply of the base currency, M1 and M2, whichshows that among the three factors of foreign exchange, central bank creditor scale and treasury stocks, the correlation between treasury stock changes and fundamental currency changes is the largest, which is the main reason for M1 changes, and the main reason for M2 changes together with foreign exchange changes. By analyzing the impact of changes in the treasury inventory balance on the money supply, Fang Yuquan, Liang Duo [11] proposes the mechanism to strengthen the treasury cash flow forecast, and gradually establish a cash flow daily forecasting mechanism. Li Yanjun [12] used the monthly sequence data since 2005 to empirically analyze the relationship between the determination of the treasury cash balance and the currency multiplier, and found that the treasury cash management mainly affects the money supply by affecting the base money. Fu Yingjun and Li Lili [13] conducted a theoretical analysis and empirical test on the impact of treasury cash management on the base currency and money supply, and found that treasury cash management has a certain degree of influence on the base currency and money supply, and the treasury cash management winning bid rate. There is a long-term equilibrium relationship with the inter-bank lending rate of commercial banks and it is relatively stable. However, with the gradual expansion of the local treasury cash management scale, the impact of treasury cash management on the money supply will become more apparent Duan Xinfeng [14] established an analytical framework for the impact of treasury fund operations on monetary policy through the monetary authority's balance sheet and extended IS-LM model, and uses OLS estimates to quantitatively analyze the impact of treasury funds on money supply, using cointegration analysis and vector error correction model(VECM)empirically analyzes the impact of treasury funds on monetary policy intermediation indicators, which show that the amount of treasury funds has become the biggest 
factor affecting the short-term fluctuation of money supply and there is a long-term equilibrium relationship between treasury funds and money supply, money supply and interbank lending rates; treasury funds and money supply. Futhermore, there is a significant negative impact between the money supply and the interbank lending rate. Wang Shuhua and Guo Liping [15] constructs a CC-LM model containing the treasury fund variable, analyzes the transmission channel and mechanism of the treasury fund's impact on the monetary policy effect from a relatively static perspective, and systematically estimates the impact effect and the Markov zoning conversion estimate, which found that changes in treasury funds have a significant positive impact on money supply and government purchase demand, but the impact on interest rates has shifted with the district system.

\section{Method}

This paper uses the taxable amount of the treasury cash management commercial bank time deposit from March 2009 to January 2011 for quantitative analysis.

\subsection{ADF Unit Root Test}

The treasury cash management operation from March 2009 to January 2011 was used for the analysis of the standard value Cash and M0, M1, M2. According to the relevant literature, in the long-term time series data, $\operatorname{lnM} 0, \operatorname{lnM} 1$ and $\operatorname{lnM} 2$ all have first-order unit roots. In the short-term data, the above four related variables are studied by ADF: Cash, $\operatorname{lnM} 0, \ln \mathrm{M} 1$ and $\ln \mathrm{M} 2$, and the statistics are as follows:

Table 1. Variable unit root test.

\begin{tabular}{llllllll}
\hline Variable & ADFstatistic & P value & conclusion & $\begin{array}{l}\text { first order } \\
\text { Differential }\end{array}$ & ADFStatistic & Pvalue & conclusion \\
\hline Cash & -2.6220 & 0.1052 & Do not reject the null hypothesis & d cash & -12.3703 & $0.000^{* * *}$ & reject the null hypothesis \\
lnM0 & 1.2263 & 0.9972 & Do not reject the null hypothesis & d lnM0 & -1.8410 & 0.3517 & Do not reject the null hypothesis \\
lnM1 & -1.5928 & 0.4693 & Do not reject the null hypothesis & d lnM1 & -4.6947 & $0.001 * * *$ & reject the null hypothesis \\
lnM2 & -1.0152 & 0.7291 & Do not reject the null hypothesis & d lnM2 & -4.6362 & $0.016 * *$ & reject the null hypothesis \\
\hline
\end{tabular}

Note: $* * *$ and $* *$ indicate the critical values of $1 \%$ and $5 \%$ significance levels, respectively.

It can be seen from the ADF test that the first-order difference of Cash, $\operatorname{lnM} 1$ and $\ln \mathrm{n} 2$ has a stationary characteristic, and the first-order difference of lnM0 still has a unit root at a significant level of $10 \%$. Therefore, Cash, $\operatorname{lnM} 1$ and $\ln M 2$ obey I (1). characteristics (as shown in Table 1).

The above table shows that the unit roots of the treasury cash variable (Cash), the narrow money supply logarithm $(\ln M 1)$, and the broad money supply logarithm $(\operatorname{lnM} 2)$ are all first-order, so these variables are differentiated to become a stationary sequence, therefore, According to ADF, it is not possible to directly analyze Cash, $\operatorname{lnM} 1$, and $\operatorname{lnM} 2$, otherwise pseudo-regression will occur. In this paper, the normality of the error term is verified by the two statistics of Jaque-Bera and Ljung-Box to ensure that the error perturbation of the VAR model is normally distributed. According to these criteria, it can be seen that Cash and lnM1 reach the minimum value of AIC and SIC (BIC) at the same time when the lag order is 2 , and then increase with the increase of the lag order, so the optimal choice of the lag order is Lagging 3 periods. Similarly, the optimal choice of the lag order of Cash and lnM2 is lag 4 (see Table 2, Table 3).

Table 2. AIC/SIC values in the treasury cash and lnM1 system.

\begin{tabular}{llll}
\hline Lag order & Guidelines & Cash & InM1 \\
\hline 2 & AIC & 9.778917 & -2.39004 \\
2 & SIC & 10.02761 & -2.14134 \\
3 & AIC & 9.637252 & -4.77412 \\
3 & SIC & 9.985759 & -4.42561 \\
4 & AIC & 9.600456 & -4.77228 \\
4 & SIC & 10.04782 & -4.32492 \\
\hline
\end{tabular}

Table 3. AIC/SIC values in the treasury cash and lnM2 system.

\begin{tabular}{llll}
\hline Lag order & Guidelines & Cash & InM1 \\
\hline 2 & AIC & 9.714108 & -6.42192 \\
2 & SIC & 9.962804 & -6.17323 \\
3 & AIC & 9.341266 & -6.58805 \\
3 & SIC & 9.689772 & -6.23954 \\
4 & AIC & 9.170737 & -6.62058 \\
4 & SIC & 9.618103 & -6.17322 \\
5 & AIC & 9.182521 & -6.8397 \\
5 & SIC & 9.726637 & -6.29559 \\
\hline
\end{tabular}

\subsection{Error Correction Term Model}

Through the error correction term model, in the cointegration system composed of Cash and $\operatorname{lnM} 1$, a simple regression is performed to test the coefficients and statistics of the independent variables in the error correction term to determine whether there is a causal relationship.

CE-Cash $=$ Cash-92.23lnM1 +816.47

$$
\left(-3.10785^{* * *}\right)
$$

CE-M1=lnM1-0.0108Cash-8.8524

$(0.00215)$

$$
\left(-8.852485^{* * *}\right)
$$

It can be seen from the error correction term model that the statistic corresponding to $\ln \mathrm{M} 1$ and Cash is -3.1 and -8.8 , which is significant at the significant level of $1 \%$, that is, Cash has a high causal relationship with $\mathrm{M} 1$, and at a significant level of $1 \%$ influences. 
Similarly, in the cointegration system consisting of Cash and $\ln \mathrm{M} 2$,

CE-Cash $=$ Cash-124.0757lnM2+1337.366

CE-M2=lnM2-0.08060Cash-10.77863

$$
\left(-2.71645^{* * *}\right)
$$

Therefore, it can be seen that the statistic corresponding to
$\operatorname{lnM} 1$ and Cash is -1.5 and -2.7 , which is significant at the significant level of $10 \%$, that is, Cash and M2 may have a causal relationship and affect each other at a significant level of $10 \%$.

\subsection{Granger Causality Test}

Check whether the operation mode of the treasury cash management is caused by M1, that is, whether M1 is the cause of the change of the treasury, and similarly, whether the change of the treasury is the cause of M1. The same method is used for M2 and Treasury fund changes. The results are shown in the following table:

Table 4. Treasury cash and money supply M1, M2 Granger causality test.

\begin{tabular}{llll}
\hline Original hypothesis & statistic & P value & conclusion (5\%) \\
\hline M1 is not the cause of Cash & 25.42079 & 0.0385 & reject the null hypothesis \\
Cash is not the cause of M1 & 74.63687 & 0.0133 & reject the null hypothesis \\
M2 is not the cause of Cash & 146.5083 & 0.0018 & reject the null hypothesis \\
Cash is not the cause of M2 & 13.52843 & 0.071 & reject the null hypothesis \\
\hline
\end{tabular}

It can be seen that through the Granger causality test, the model constructed by the percentage change of the treasury cash and the money supply M1 (lnM1) and the percentage change of the money supply M2 (lnM2) has a two-way causal relationship, the treasury cash ( Cash) is not the percentage change of the money supply M1 (lnM1) Granger is rejected because of the $1.3 \%$ significant level under H0, the treasury cash (Cash) is not the percentage change of the money supply M2 (lnM2) Granger due to $0.1 \%$ under H0 Significant level was rejected, the percentage change of money supply M1 $(\operatorname{lnM} 1)$ is not the treasury cash (Gasher) is rejected because of the $7 \%$ significant level under $\mathrm{H} 0$, the percentage change of money supply M2 (lnM2) is not the treasury cash (Cash) The Granger was rejected for a significant level of $0.2 \%$ under $\mathrm{H} 0$.

\subsection{Impulse Response Analysis}

The Granger causality test reflects the directionality of the relationship between the treasury cash and the money supply. This paper uses the impulse response method to analyze the dynamic change process of the treasury cash quota to the various levels of money supply. In most cases, the variance covariance matrix of the error dispersive term of the estimation equations listed in the VAR model is non-diagonal, so it is first necessary to orthogonally process it to obtain the corresponding diagonalization moment, where Choleski decomposition is existing. The most common method in the literature. Through the Choleski decomposition and the impulse response diagram, the degree and condition of the interaction between the variables of $\operatorname{lnM} 1$ and $\operatorname{lnM} 2$ under different lag orders can be obtained.

According to the impulse response function, the impulse response relationship between the treasury cash and the money supply (lnM1, lnM2) is shown in the above figure. The unit impact on the treasury cash operation and management has led to the obvious occurrence of both M1 and M2.

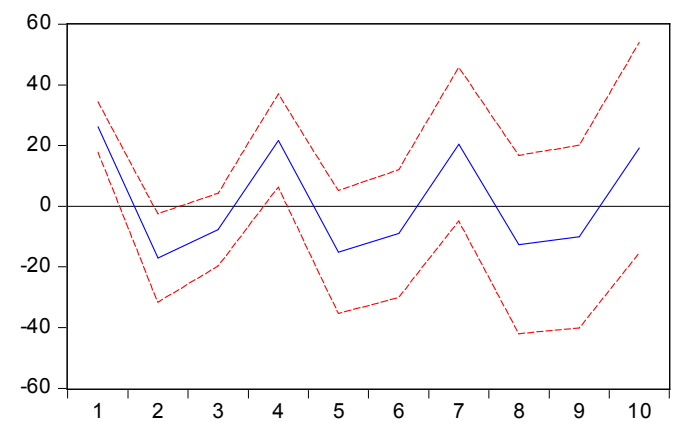

Figure 1. Response of CASH to CASH.

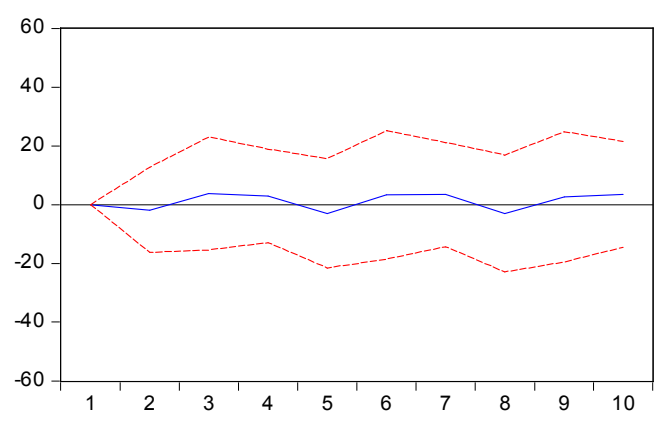

Figure 2. Response of CASH to LNMI.

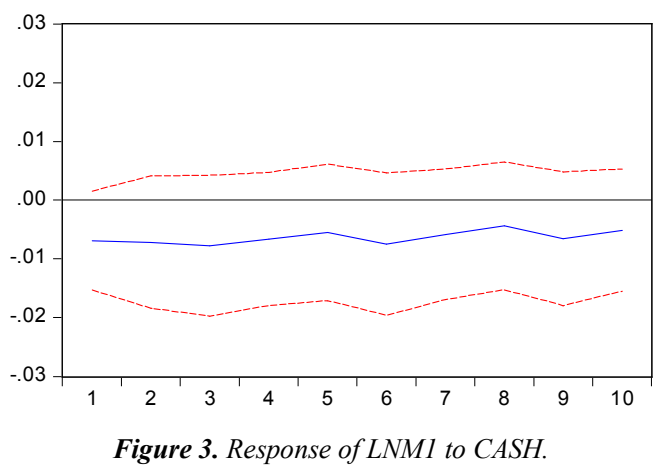

Figure 3. Response of LNM1 to CASH. 

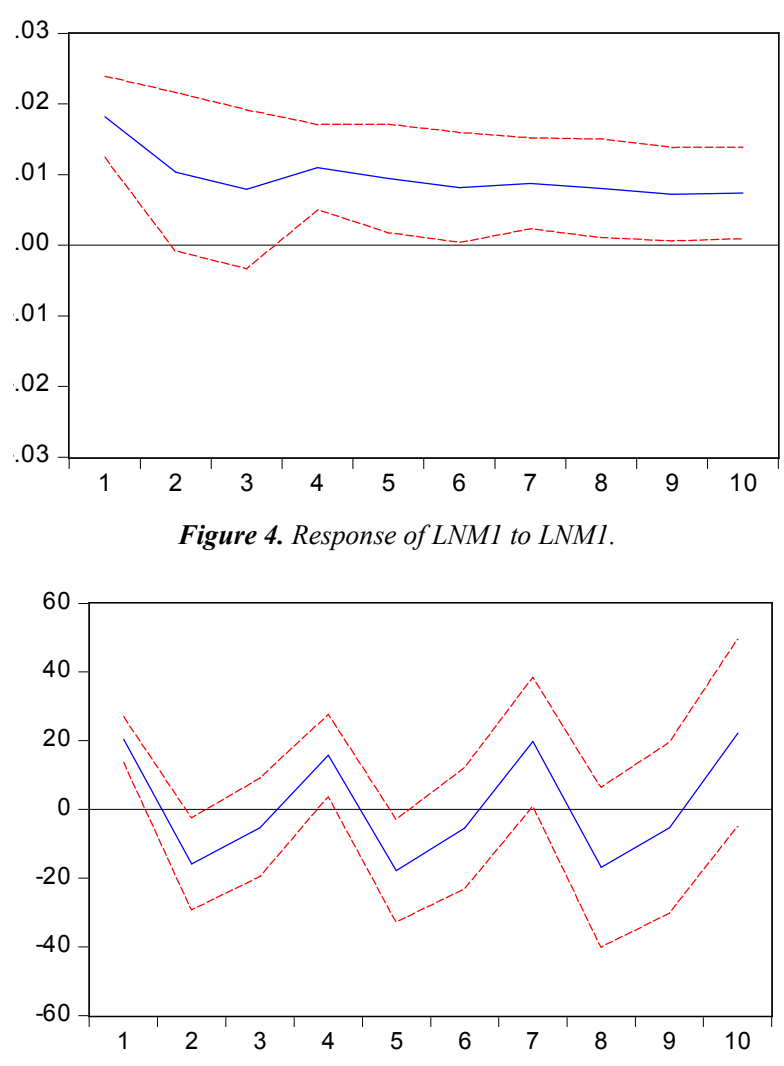

Figure 5. Response of $\mathrm{CASH}$ to $\mathrm{CASH}$.

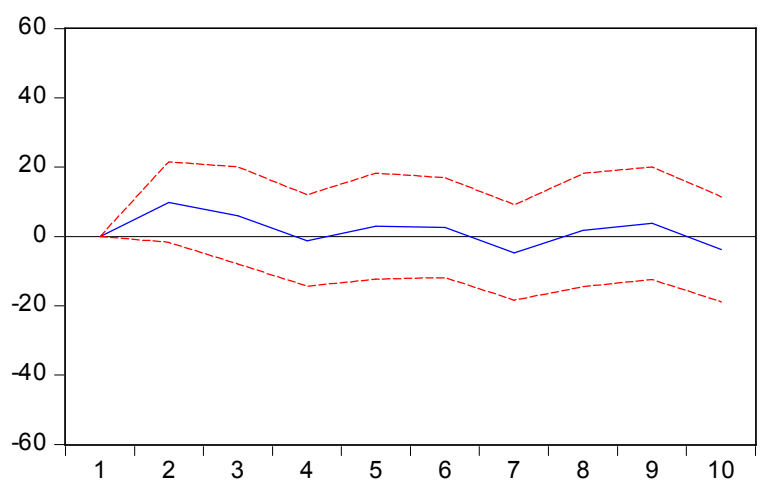

Figure 6. Response of CASH to LNM2.

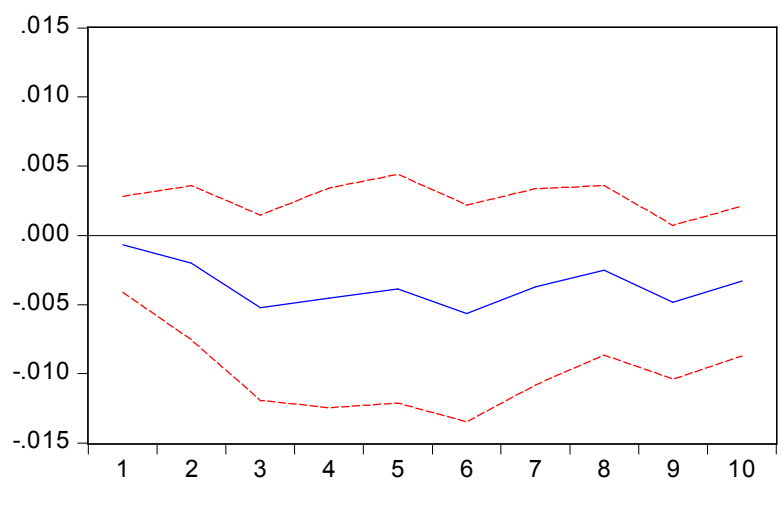

Figure 7. Response of LNM2 to CASH.

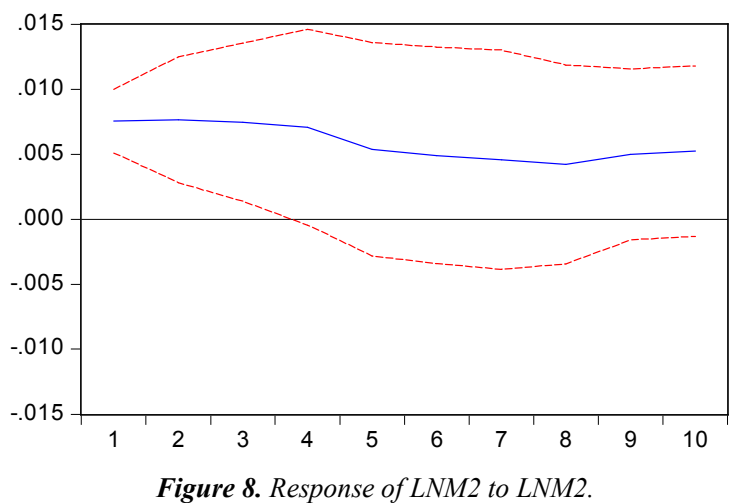

\section{Conclusion}

From the empirical analysis, it can be seen that the treasury cash management operation has caused significant changes in both $\ln \mathrm{M} 1$ and $\ln \mathrm{M} 2$. In the initial stage, both $\ln \mathrm{M} 1$ and $\operatorname{lnM} 2$ have a negative response to the positive impact of the treasury cash, and the reaction trajectory presents a positive U-shaped, parabolic form. In the first 6 months of the shock, the currency lnM1 gradually decreased. By the sixth month, the impact on $\ln \mathrm{M} 1$ reached the lowest point, then the impact on $\operatorname{lnM} 1$ gradually decreased, while the reaction curve gradually increased. Thus the effect was always negative, indicating that the increase in treasury cash does result in a decline in the percentage change in money supply.

\section{References}

[1] Warren B. Hrung. An Examination of Treasury Term [J]. FRBNY Economic Policy Review, 2007: 19-32.

[2] Lynch, TD, Shamsub. H. \& Onwujuba. C. A Strategy to Prevent Losses in Local Government Investment Pools [J]. Public Budgeting \& Finance, 2002, 2 (1): 60-79.

[3] Jones. G. \& Bowrey. G. Local Government Investment: A Form of Gambling [J]. Australasian Journal of Regional Studies, 2010, 16 (1): 37-50.

[4] Bordo MD, Duca JV, Koch C. Economic Policy Uncertainty and the Credit Channel: Aggregate and Bank Level U.S. Evidence over Several Decades [J]. Journal of Financial Stability, 2016: S1572308916300559.

[5] Chen Jianqi, Zhang Yuan. The Impact of Treasury Cash Transfer Commercial Banks on Money Supply Policy_Based on the Expansion Analysis of Commercial Bank's Asset and Liability Framework [J]. Financial Research, 2010 (7): 85-98.

[6] Wang Wensu, Zhou Jiannan, Ning Fangjing. The Choice of Coordination Mode of Treasury Cash Management and Monetary Policy [J]. Local Finance Research, 2013 (9): 41-55.

[7] Ye Xiaodong, Du Jinxi. The Impact of the Treasury Cash Deposited in the Central Bank on Monetary Policy [J]. Financial Economics Research, 2014, 29 (02): 36-43.

[8] Bai Yanfeng, Li Longyu, Jin Wei. Treasury Cash Flow Forecast Based on New Perspectives of Macroeconomic Factors [J]. Journal of Hunan Finance and Economics Institute, 2014 (6): 5-16. 
[9] Yang Yuxia, Lou Qingyi. Analysis of the Monetary Effect of the Changes in the Treasury Cash Balance [J]. Local Finance Research, 2014 (02): 23-26.

[10] Zhang Xiaobin. The Impact of Treasury Stock Changes on Money Supply_-Based on the Analysis Framework of Central Bank's Balance Sheet Structure [J]. Shanghai Finance, 2016 (6): 27-32.

[11] Fang Yuquan, Liang Duo. Discussion on the Change of Treasury Stock Balance and the Effectiveness of Monetary Policy Implementation [J]. Northern Finance, 2017 (11): 80-81.

[12] Li Yanjun. Treasury cash management: an alternative channel for current liquidity in China [J]. Public Finance Research, 2017 (3): 49-59.
[13] Fu Yingjun, Li Lili. Empirical Test of the Influence of Treasury Cash Management on Money Supply and Interest Rate [J]. Statistics and Decision, 2017 (6): 165-169.

[14] DuanXinfeng. An Empirical Study of the Influence of Treasury Funds on Monetary Policy__ A Quantitative Analysis Based on Co-integration and Vector Error Correction Model [J]. Contemporary Finance Research, 2019 (02): 19-35.

[15] Wang Shuhua, GuoLiping. The Dynamic Impact Mechanism of Treasury Fund Fluctuation and China's Monetary Policy Effect_-An Empirical Analysis of System Estimation and District System Conversion [J]. Journal of Contemporary Economics, 2019, 41 (2): 13-26. 